\title{
Prevalence of clarithromycin-resistant Helicobacter pylori strains in gastric mucosa-associated lymphoid tissue lymphoma patients
}

\author{
Ceren Bilgilier $^{1}$ - Ingrid Simonitsch-Klupp ${ }^{2}$ • Barbara Kiesewetter ${ }^{3}$ - Markus Raderer $^{3}$. \\ Werner Dolak $^{4} \cdot$ Athanasios Makristathis $^{5} \cdot$ Christoph Steininger $^{1}$
}

Received: 15 January 2016/Accepted: 8 April 2016/Published online: 19 April 2016

(C) The Author(s) 2016. This article is published with open access at Springerlink.com

\begin{abstract}
Gastric MALT lymphoma is closely associated with Helicobacter pylori infection. Bacterial eradication therapy comprising clarithromycin is the first-line treatment in gastric MALT lymphoma patients. However, antimicrobial resistance to clarithromycin has been increasing in Europe, and thus far, it has not been examined in gastric MALT lymphoma patients. Based upon histopathological investigation, 17 adult gastric MALT lymphoma patients were identified to be related with $H$. pylori infection between 1997 and 2014 . Detection of $H$. pylori infection in these patients and clarithromycin susceptibility testing were performed by $23 \mathrm{~S}$ rRNA gene real-time PCR. Twelve of the patients were confirmed with $H$. pylori infection by real-time PCR. Among these patients, only two were found to be infected with clarithromycin-resistant $H$. pylori strain. In one of them, both the clarithromycin-resistant and sensitive genotype were detected. The rate of clarithromycin resistance was $15.4 \%$. Clarithromycin resistance pattern in gastric MALT lymphoma patients is under the predictions since a previous study performed in Central Europe revealed a rate of $36.6 \%$ in Austria.
\end{abstract}

Christoph Steininger

christoph.steininger@meduniwien.ac.at

1 Department of Internal Medicine I, Division of Infectious Diseases and Tropical Medicine, Medical University of Vienna, Währinger Gürtel 18-20, 1090 Vienna, Austria

2 Clinical Institute of Pathology, Medical University of Vienna, Vienna, Austria

3 Department of Internal Medicine I, Division of Oncology, Medical University of Vienna, Vienna, Austria

4 Department of Internal Medicine III, Division of Gastroenterology and Hepatology, Medical University of Vienna, Vienna, Austria

5 Department of Laboratory Medicine, Division of Clinical Microbiology, Medical University of Vienna, Vienna, Austria
Considering the low antimicrobial resistance rate, clarithromycin is still an option in gastric MALT lymphoma management.

Keywords Helicobacter pylori - Gastric mucosa-associated lymphoid tissue lymphoma · Antimicrobial resistance .

Clarithromycin $\cdot \operatorname{cag} A$

\section{Introduction}

Extranodal marginal zone lymphoma of mucosa-associated lymphoid tissue (MALT) lymphoma most commonly affects the stomach where it accounts for almost $50 \%$ of all gastric lymphomas [1-3]. Still, gastric MALT lymphoma is a rare disease and therapeutic recommendations are mostly based on retrospective data and clinical experience, while only few randomized controlled data are available [4].

Current evidence strongly supports a causal role of Helicobacter pylori infection in the evolution of the disease, and antibiotic treatment is the therapeutic mainstay of management of such patients. In almost $90 \%$ of cases, gastric MALT lymphoma is thought to be associated with infection with this microaerophilic, Gram-negative bacterium, although recent studies have shown a much higher rate of $H$. pylorinegative patients [4-6]. We could confirm recently this trend in an Austrian cohort by observing a rate of $H$. pylori-negative cases of MALT lymphoma of $32 \%$ [7]. Still, patients with gastric MALT lymphoma are significantly more likely to have evidence of previous $H$. pylori infection than matched controls [8]. Eradication of $H$. pylori infection is associated with regression of gastric MALT lymphoma in the large majority of patients and has been reported to be beneficial even in patients without laboratory confirmation of $H$. pylori infection $[3,7$, 9]. The most widely accepted hypothesis for the pathogenesis 
of gastric MALT lymphoma states accordingly that $H$. pylori infection of the stomach indirectly stimulates B cells by activation of $\mathrm{CD}^{+} \mathrm{T}$ cells and also CagA is translated into lymphoma cells $[10,11]$. Consecutively, a chronic activation of $B$ cells and local inflammation with the generation of free reactive oxygen species triggers the evolution of gastric MALT lymphoma [11].

Accordingly, H. pylori eradication is recommended by all current international guidelines as first-line treatment for patients suffering from gastric MALT lymphoma, irrespective of stage $[2,3,12]$. The standard treatment regimen recommended for $H$. pylori eradication consists of a clarithromycin-based triple therapy, also including a proton pump inhibitor (PPI) twice a day and amoxicillin or metronidazole for 7 or 14 days [3]. Nevertheless, antimicrobial resistance rates have been increasing dramatically in clinical $H$. pylori strains. In Europe, resistance rates to the key antimicrobial clarithromycin range between 5.6 and $36.6 \%$, with Austria leading the table [13]. Evaluation of clinical H. pylori strains for antimicrobial resistance is recommended for patients with treatment failures, as well as those originating from geographic regions with high rates of antimicrobial resistance [4]. However, in gastric MALT lymphoma patients, bacterial culture has a clearly lower sensitivity than histology even if performed under optimized conditions [14], thereby limiting the utility of data regarding antimicrobial resistance. As a consequence, the optimum antimicrobial combination treatment in gastric MALT lymphoma patients from geographic regions with high resistance rates remains yet to be defined.

In this study, we therefore evaluated genotypic clarithromycin resistance rates of clinical H. pylori strains in a cohort of gastric MALT lymphoma patients through utilizing a highly sensitive and reliable real-time PCR assay. We found that clarithromycin resistance rates are clearly lower in gastric MALT lymphoma patients than anticipated from epidemiological information in the general population.

\section{Materials and Methods}

Patients Patients eligible for this retrospective, monocentric analysis had a histological confirmation of gastric MALT lymphoma diagnosed between January 1997 and December 2014. In addition, only gastric biopsy samples that were histologically positive for Helicobacter-like organisms (HLO) were included in the present study. The presence of $H$. pylori could be further confirmed with use of VENTANA anti-H. pylori (SP48) rabbit monoclonal primary antibody (Roche Diagnostics, Basel, Switzerland). Only cases with sufficient archived primary tumour tissue were selected. Demographic and clinical data were collected retrospectively from patients' notes and prescription charts. The study was performed in accordance with the Declaration of Helsinki and good clinical practice guidelines and was approved by the local ethics committee (EK1548/2014). Informed consent was obtained for the diagnostic procedures from all individual participants included in the study.

DNA purification Genomic DNA was extracted from representative formalin-fixed, paraffin-embedded tissue blocks of biopsy samples collected from gastric MALT lymphoma patients. DNA was purified using an EZ1 DNA Tissue kit (No. 953034; Qiagen, Hilden, Germany) according to the tissue protocol followed by automated purification using the EZ1 instrument.

Microbiological evaluation All HLO-positive biopsy samples available from the present gastric MALT lymphoma patients were tested for the presence of $H$. pylori-specific DNA with use of a previously described assay [15]. In brief, this PCR assay amplifies a H. pylori DNA fragment of $137 \mathrm{bp}$ of the 23S rRNA gene including the sites of mutation that confer phenotypic resistance to clarithromycin. Isolated DNA was subjected to 70 amplification cycles (with a temperature transition rate of $20^{\circ} \mathrm{C} / \mathrm{s}$ ) of denaturation at $95{ }^{\circ} \mathrm{C}$ for $5 \mathrm{~s}$, annealing at $65^{\circ} \mathrm{C}$ for $10 \mathrm{~s}$, and primer extension at $72{ }^{\circ} \mathrm{C}$ for $6 \mathrm{~s}$. The limit of detection of this PCR assay for pure H. pylori DNA was $4 \mathrm{fg}$ per PCR, which is equivalent to 2.2 bacteria and H. pylori specificity and sensitivity of this PCR assay was confirmed to be 98 and $100 \%$, respectively. Genotypic clarithromycin resistance of clinical H. pylori strains was evaluated with use of melting point analysis performed after the amplification of the 23S rRNA gene as described previously. For this purpose, a probe binding to the site of mutations in the 23S rRNA gene was used during amplification. Melting temperatures were analysed for significant differences to the wildtype $H$. pylori genotype (the melting temperature is lower in mutated strains than in wild type, clarithromycin-sensitive strains because of the mismatch between the amplicon and the probe, which corresponds to the wild-type susceptible genotype). Every PCR run included several positive and negative controls. As positive controls, DNA samples extracted from pure clarithromycin-sensitive and resistant $H$. pylori isolates were used. As negative control, master mix solution filled up with water to the final volume was applied.

PCR amplification of the cagA variable region was performed as previously described by using the primers and conditions with some modifications [16]. Primers were modified to account for the mismatches at primer binding sites among the different $H$. pylori cagA genotypes available through GenBank (Table 1). Alignment of sequences was done using CLC Genomics Workbench Software (CLC bio, QIAGEN, Hilden, Germany). First screening of samples was done with use of the EPIYA PCR using the forward primer CagA-Tfw and three reverse primers (CagA-rvP1, CagA-rvP2, and CagA-rvP3) to amplify the three different EPIYA sites of the 
Table 1 Primers used for $\operatorname{cag} A$ amplification

\begin{tabular}{ll}
\hline Primer & Sequence $\left(5^{\prime}-3^{\prime}\right)$ \\
\hline CagA-Tfw & GGAACCCTAGTCGGTAATG \\
CagA-Trv & ATCTTTGAGMTTGTCTATCG \\
CagA-rvP1 & GTCCTGYTTTCTTTTTATTAACYTKAGC \\
CagA-rvP2 & TTTAGCAACTTGAGYRTAAATGGG \\
CagA-rvP3 & ATCAATYGTAGCATAAATGGG \\
\hline
\end{tabular}

$(\mathrm{M}=\mathrm{A}+\mathrm{C}, \mathrm{Y}=\mathrm{T}+\mathrm{C}, \mathrm{K}=\mathrm{G}+\mathrm{T}$, and $\mathrm{R}=\mathrm{G}+\mathrm{A})$

cagA gene, $\mathrm{P} 1, \mathrm{P} 2$, and $\mathrm{P} 3$, and thereby determine the EPIYA motifs encoded. To exclude a low sensitivity of this PCR assay as possible explanation for negative test results, a second $\operatorname{cag} A$-specific PCR that amplifies the entire 3 ' repeat regions of the $\operatorname{cag} A$ gene was performed using the forward primer CagA-Tfw and reverse primer CagA-Trv. In present study, iProof DNA polymerase (Bio-Rad Laboratories, Hercules, CA) was used, which has the $3^{\prime}$ to $5^{\prime}$ exonuclease proofreading activity and may be more accurate than Taq polymerase. A reaction mixture containing $0.2 \mathrm{mM}$ of each deoxynucleoside triphosphate, $3 \mathrm{mM} \mathrm{MgCl} 2,0.5 \mu \mathrm{M}$ of both forward and reverse primers, $3 \% \mathrm{DMSO}, 0.02 \mathrm{U}$ of iProof DNA polymerase $/ \mu 1,1 \times$ iProof HF Buffer (Bio-Rad Laboratories, Hercules, CA), and $1 \mu \mathrm{l}$ of DNA was used. The mixture was incubated at $98{ }^{\circ} \mathrm{C}$ for $30 \mathrm{~s}$, followed by 35 cycles at $98^{\circ} \mathrm{C}$ for $10 \mathrm{~s}, 57^{\circ} \mathrm{C}$ for $15 \mathrm{~s}$, and $72{ }^{\circ} \mathrm{C}$ for $15 \mathrm{~s}$, and a final extension at $72{ }^{\circ} \mathrm{C}$ for $5 \mathrm{~min}$. The resulting PCR products were analysed on $2 \%$ agarose gel.

\section{Results}

From January 1997 to December 2014, a total of 97 patients with gastric MALT lymphoma were evaluated and treated at Vienna General Hospital, Austria as previously described [7]. A total of seven patients ( $7 \%$ ) had detectable HLO in gastric biopsies at the time of evaluation. In one patient, HLO could be detected in three samples collected over a period of 3 years. In addition, we also evaluated gastric biopsy samples collected from additional ten patients who were treated at other institutions over the same period and whose samples were sent to our institution for histological evaluation. HLO were detected in all of these ten samples as well. The mean age $( \pm \mathrm{SD})$ of the 17 patients was $72 \pm 9$ years (range, $57-88$ years) and $71 \%$ (12 of 17) of them were male. Remarkably, seven ( $41 \%$ ) of the 17 MALT lymphoma patients received eradication therapy for $\mathrm{H}$. pylori before the present detection of HLO in their gastric biopsies.

Histological evaluation further confirmed the presence of signs of gastritis in all 19 gastric biopsy samples from the 17 patients. Semi-quantitative evaluation of HLO density in the samples showed low density in eight, intermediate density in six, and high density in five samples.

Isolation of DNA from formalin-fixed tissue samples and testing with the $H$. pylori-specific PCR assay yielded positive test results in 14 (74 \%) of the 19 histologically HLO-positive samples. These $14 \mathrm{H}$. pylori-positive samples were collected from 13 different gastric MALT lymphoma patients. A falsenegative PCR result was not associated significantly with a low HLO density in the gastric biopsy samples (4/8 vs $1 / 11$; $P=0.111$ [Fisher Exact]). Analysis of the 23S rRNA gene for genotypic clarithromycin resistance revealed sensitive strains in $11(79 \%)$ of the 14 samples. Clarithromycin-resistant H. pylori strains could be detected only in two different samples from a single patient and in the sample from a further patient, in which a mixed genotype was detected. The rate of clarithromycin-resistant $H$. pylori infections was accordingly $15 \%$ (2 of 13$)$.

Follow-up studies revealed that $H$. pylori infection was eradicated successfully in all five patients with information available. Remarkably, the single patient with repeated detection of a clarithromycin-resistant $H$. pylori strain was eradicated successfully between these positive test results as indicated by a negative histological evaluation of gastric biopsies. Upon follow-up gastric biopsies, however, the patient's samples were again positive for $H$. pylori indicative for reinfection by a clarithromycin-resistant $H$. pylori strain. Eight patients were lost to follow-up due to gastrectomy $(n=1)$, an additional malignancy requiring immediate chemotherapy or rapid progression of MALT lymphoma $(n=3)$, or unknown reasons $(n=4)$.

In addition, we tested the gastric biopsy samples for the presence of the $\operatorname{cag} A$ because $H$. pylori strains possessing that gene are more likely to cause disease than those lacking it [17-19]. All samples tested by EPIYA PCR were negative for the $\operatorname{cag} A$. To avoid a bias by a limited sensitivity of this PCR, we tested all samples also with a more sensitive pan$\operatorname{cag} A$ PCR with the same results.

\section{Discussion}

Antimicrobial eradication treatment is the mainstay in the management of gastric MALT lymphoma patients based on the recognition of a likely causal role of $H$. pylori infection in the evolution of the disease and excellent response rates to antimicrobial combination treatment $[7,20]$. H. pylori antimicrobial resistance rates, however, increased clearly in the last decade with clarithromycin resistance rates as high as $37 \%$ [13]. Contrary to our initial expectation, we found that clarithromycin resistance rates were as low as $15 \%$ in the present cohort of gastric MALT lymphoma patients which suggests that clarithromycin is still an effective choice in the empiric eradication of $H$. pylori infection. 
The standard antimicrobial regimen recommended for $H$. pylori eradication in the general population as well as in patients with gastric MALT lymphoma is based on a clarithromycin-backbone substituted with a PPI and amoxicillin or metronidazole for 7 or 14 days [3]. The increase in antimicrobial resistance, particularly in Central Europe, required a switch to second-line regimens in empiric eradication therapy [21]. Second-line treatments, however, are associated with a higher pill burden, higher rates of adverse events, and the risk to induce antimicrobial resistance in other infectious pathogens. In view of the limited information available on H. pylori antimicrobial resistance patterns in patients with gastric MALT lymphoma, data from the general population suggest that second-line regimens might also be required in the case of these patients. Our analyses, however, reveal a clarithromycin resistance rate as low as $15.4 \%$, which is clearly lower than expected from the high resistance rate of $37 \%$ observed previously in Austria. Although the present observations have to be interpreted with caution due to the small size of the cohort studied, first-line antimicrobial eradication regimens still appear to be effective options for empiric treatment.

To determine the presence of $H$. pylori infection in gastric MALT lymphoma patients, a combination of several diagnostic techniques is advised by international guidelines, including invasive (e.g., histology, rapid urease test, or bacterial culture) and non-invasive techniques (e.g., serology and urea breath test) [2]. Establishing the diagnosis of $H$. pylori infection in gastric MALT lymphoma patients, however, may be difficult. Results obtained through the use of histology, bacterial culture, PCR, and serology are concordant only in $63 \%$ of cases [14]. For the detection of H. pylori in gastric MALT lymphoma patients, bacterial culture of gastric biopsy samples was found to be unsatisfactory, when the generally high sensitivity of bacterial culture for the detection of infectious pathogens is considered, in a diversity of clinical samples [14].

Prevalence of $H$. pylori infection would be underestimated if only one diagnostic tool would be used. Still, we could identify HLO with use of histology only in seven of 97 gastric biopsy samples. The very small number of gastric MALT lymphoma patients with detectable HLO in their gastric biopsy samples requires explanation. Information on the prevalence of HLO positivity in gastric MALT lymphoma patients is still limited to a few case series [14]. In a large European cohort study, histology was positive for HLO in 29 of 90 patients with gastric MALT lymphoma. The present retrospective study was conducted at a tertiary hospital, and we may not exclude selection biases deriving from previous eradication therapies prescribed before referral, as well as a trend towards evaluation and management of more advanced stages of the disease [7]. Accordingly, it may currently be only hypothesized on the true prevalence of $H$. pylori positivity in gastric MALT lymphoma patients when direct diagnostic assays are used.

The presence of $H$. pylori in gastric biopsy samples could be confirmed by PCR in $74 \%$ of samples that were HLO positive by histology. The PCR assay used was thoroughly evaluated and is highly sensitive [15] but, in the present study, was used for the detection of $H$. pylori-specific DNA in formalin-fixed, paraffin-embedded tissue samples. Formalin treatment also fragments DNA and traps it by extensive cross-linking between nucleic acid strands [22]. Moreover, the likelihood of a positive PCR assay did not correlate with the density of $H$. pylori in the tissue samples, which points rather to a technical than to a biological explanation for negative PCR results. DNA isolated from formalin-fixed, paraffin-embedded tissue samples is, therefore, of poor quality overall, and pose a major challenge for the detection of specific DNA targets.

Nevertheless, negative test results obtained with use of the H. pylori-specific PCR assay may also be explained by infection with Helicobacter heilmannii. A minority of gastric MALT lymphomas is associated with infection by H. heilmannii, which is difficult to differentiate from H. pylori when using standard stains in histology. Nevertheless, we also evaluated PCR-negative tissue samples with use of $H$. pylori-specific immunohistochemistry and found that the HLO detected were actually $H$. pylori. Accordingly, negative PCR results obtained from evaluation of formalin-fixed, paraffin-embedded tissue samples have to be interpreted with caution.

The evolution of gastric MALT lymphoma has been related specifically to $H$. pylori strains expressing the cag pathogenicity island, which is an important virulence factor in this infection [17]. WHO and International Agency for Research on Cancer define $\operatorname{cag} A$ as a human class I carcinogen $[23,24]$. Upon $H$. pylori infection, CagA is translocated into gastric epithelial cells where it deregulates intracellular signalling pathways and thereby promotes lymphomagenesis [10]. H. pylori strains that do not encode $\operatorname{cag} A$ were associated with resistance to metronidazole, but not to clarithromycin [25-27]. CagA-specific antibodies are found in 89-96\% of sera from patients with gastric MALT lymphoma $[18,19]$. In a previous study, the $\operatorname{cag} A$ gene was detected in $47 \%$ of H. pylori strains from gastric MALT lymphoma patients [14]. In contrast, we were not able to identify a single patient harbouring a $\operatorname{cag} A$-encoding $H$. pylori strain. The negative test results may again be attributable to the low quality of DNA recovered from formalin-treated biopsy samples. Still, we used two different and sensitive PCR assays to avoid false-negative test results [28]. A significant difference to the previous study, however, is the material used; we used primary samples whereas cultured bacteria were used in the previous study. 
In conclusion, the antimicrobial resistance to clarithromycin in H. pylori strains obtained from gastric MALT lymphoma patients is relatively low and clarithromycin is still a valid choice in empiric eradication treatment. The presence of clarithromycin-resistant $H$. pylori strains, however, should be considered in patients with treatment failure.

Acknowledgments Open access funding provided by Medical University of Vienna.

\section{Compliance with ethical standards}

Conflict of interest No conflicts of interest to declare

Open Access This article is distributed under the terms of the Creative Commons Attribution 4.0 International License (http:// creativecommons.org/licenses/by/4.0/), which permits unrestricted use, distribution, and reproduction in any medium, provided you give appropriate credit to the original author(s) and the source, provide a link to the Creative Commons license, and indicate if changes were made.

\section{References}

1. Zucca E, Bertoni F, Roggero E, Cavalli F (2000) The gastric marginal zone B-cell lymphoma of MALT type. Blood 96:410-419

2. Gisbert JP, Calvet X (2011) Review article: common misconceptions in the management of Helicobacter pylori-associated gastric MALT-lymphoma. Aliment Pharmacol Ther 34:1047-1062

3. Nakamura S, Matsumoto T (2013) Helicobacter pylori and gastric mucosa-associated lymphoid tissue lymphoma: recent progress in pathogenesis and management. World J Gastroenterol 19:8181-8187

4. Ruskoné-Fourmestraux A, Fischbach W, Aleman BM, Boot H, Du MQ, Megraud F, Montalban C, Raderer M, Savio A, Wotherspoon A, EGILS group (2011) EGILS consensus report. Gastric extranodal marginal zone B-cell lymphoma of MALT. Gut 60:747-758

5. Swerdlow SH, Campo E, Harris NL, Jaffe ES, Pileri SA, Stein H, Thiele J, Vardiman JW (2008) The World Health Organization classification of tumours of haematopoietic and lymphoid tissues. WHO, Lyon

6. Zucca E, Copie-Bergman C, Ricardi U, Thieblemont C, Raderer M, Ladetto M, ESMO Guidelines Working Group (2013) Gastric marginal zone lymphoma of MALT type: ESMO Clinical Practice Guidelines for diagnosis, treatment and follow-up. Ann Oncol 24(Suppl 6):vi144-vi148

7. Raderer M, Wöhrer S, Kiesewetter B, Dolak W, Lagler H, Wotherspoon A, Muellauer L, Chott A (2015) Antibiotic treatment as sole management of Helicobacter pylori-negative gastric MALT lymphoma: a single center experience with prolonged follow-up. Ann Hematol 94:969-973

8. Parsonnet J, Hansen S, Rodriguez L, Gelb AB, Warnke RA, Jellum E, Orentreich N, Vogelman JH, Friedman GD (1994) Helicobacter pylori infection and gastric lypmhoma. N Engl J Med 330:1267-1271

9. Vannata B, Stathis A, Zucca E (2015) Management of the marginal zone lymphomas. In: Evens AM, Blum KA (eds) Non-Hodgkin lymphoma. Springer International Publishing, Switzerland, pp 227-249

10. Lin WC, Tsai HF, Kuo SH, Wu MS, Lin CW, Hsu PI, Cheng AL, Hsu PN (2010) Translocation of Helicobacter pylori CagA into human B lymphocytes, the origin of mucosa-associated lymphoid tissue lymphoma. Cancer Res 70:5740-5748
11. Peng JC, Zhong L, Ran ZH (2015) Primary lymphomas in the gastrointestinal tract. J Dig Dis 16:169-176

12. Zullo A, Hassan C, Cristofari F, Perri F, Morini S (2010) Gastric lowgrade mucosal-associated lymphoid tissue-lymphoma: Helicobacter pylori and beyond. World J Gastrointest Oncol 2:181-186

13. Megraud F, Coenen S, Versporten A, Kist M, Lopez-Brea M, Hirschl AM, Andersen LP, Goossens H, Glupczynski Y, Study Group participants (2013) Helicobacter pylori resistance to antibiotics in Europe and its relationship to antibiotic consumption. Gut 62:34-42

14. Lehours P, Ruskone-Fourmestraux A, Lavergne A, Cantet F, Mégraud F (2003) Which test to use to detect Helicobacter pylori infection in patients with low-grade gastric mucosa-associated lymphoid tissue lymphoma? Am J Gastroenterol 98:291-295

15. Schabereiter-Gurtner C, Hirschl AM, Dragosics B, Hufnagl P, Puz S, Kovách Z, Rotter M, Makristathis A (2004) Novel real-time PCR assay for detection of Helicobacter pylori infection and simultaneous clarithromycin susceptibility testing of stool and biopsy specimens. J Clin Microbiol 42:4512-4518

16. Argent RH, Zhang Y, Atherton JC (2005) Simple method for determination of the number of Helicobacter pylori CagA variableregion EPIYA tyrosine phosphorylation motifs by PCR. J Clin Microbiol 43:791-795

17. Wang HP, Zhu YL, Shao W (2013) Role of Helicobacter pylori virulence factor cytotoxin-associated gene A in gastric mucosaassociated lymphoid tissue lymphoma. World J Gastroenterol 19: 8219-8226

18. Fischbach W, Jung T, Goebeler-Kolve M, Eck M (2000) Comparative analysis of the Helicobacter pylori status in patients with gastric MALT-type lymphoma and their respective spouses. Z Gastroenterol 38:627-630

19. Eck M, Schmausser B, Haas R, Greiner A, Czub S, MüllerHermelink HK (1997) MALT-type lymphoma of the stomach is associated with Helicobacter pylori strains expressing the CagA protein. Gastroenterology 112:1482-1486

20. Raderer M, Streubel B, Wöhrer S, Häfner M, Chott A (2006) Successful antibiotic treatment of Helicobacter pylori negative gastric mucosa associated lymphoid tissue lymphomas. Gut 55:616-618

21. Malfertheiner P, Megraud F, O'Morain CA, Atherton J, Axon AT, Bazzoli F, Gensini GF, Gisbert JP, Graham DY, Rokkas T, El-Omar EM, Kuipers EJ, The European Helicobacter Study Group (2012) Management of Helicobacter pylori infection - the Maastricht IV/ Florence Consensus Report. Gut 61:646-664

22. Dedhia P, Tarale S, Dhongde G, Khadapkar R, Das B (2007) Evaluation of DNA extraction methods and real time PCR optimization on formalin-fixed paraffin-embedded tissues. Asian Pac J Cancer Prev 8:55-59

23. Meine GC, Rota C, Dietz J, Sekine S, Prolla JC (2011) Relationship between cagA-Positive Helicobacter pylori infection and risk of gastric cancer: a case control study in Porto Alegre, RS, Brazil. Arq Gastroenterol 48:41-45

24. Uemura N, Okamoto S, Yamamoto S, Matsumura N, Yamaguchi S, Yamakido M, Taniyama K, Sasaki N, Schlemper RJ (2001) Helicobacter pylori infection and the development of gastric cancer. N Engl J Med 345:784-789

25. Fasciana T, Calà C, Bonura C, Di Carlo E, Matranga D, Scarpulla G, Manganaro M, Camilleri S, Giammanco A (2015) Resistance to clarithromycin and genotypes in Helicobacter pylori strains, isolated in Sicily. J Med Microbiol. doi:10.1099/jmm.0.000163

26. Liou JM, Chang CY, Chen MJ, Chen CC, Fang YJ, Lee JY, Wu JY, Luo JC, Liou TC, Chang WH, Tseng CH, Wu CY, Yang TH, Chang CC, Wang HP, Sheu BS, Lin JT, Bair MJ, Wu MS, Taiwan Gastrointestinal Disease and Helicobacter Consortium (2015) The primary resistance of helicobacter pylori in Taiwan after the national policy to restrict antibiotic consumption and its relation to 
virulence factors - a Nationwide Study. PLoS One. doi:10.1371/ journal.pone.0124199

27. Taneike I, Nami A, O'Connor A, Fitzgerald N, Murphy P, Qasim A, O'Connor H, O'Morain C (2009) Analysis of drug resistance and virulence-factor genotype of Irish Helicobacter pylori strains: is there any relationship between resistance to metranidazole and $\operatorname{cag} A$ status? Aliment Pharmacol Ther 30: 784-790

28. Bustamante-Rengifo JA, Matta AJ, Pazos A, Bravo LE (2013) In vitro effect of amoxicillin and clarithromycin on the $3^{\prime}$ region of cagA gene in Helicobacter pylori isolates. World J Gastroenterol 19:6044-6054 